\title{
EARTHQUAKE PROGNOSTICATION IN THE SOVIET UNION
}

\author{
By Igor Nersesov*
}

\begin{abstract}
Editor's Note: This paper was written for the Bulletin at the request of the Novosti Press Agency, Moscow, and forwarded through the Information Section, Legation of the USSR, Wellington.
\end{abstract}

Being able to predict an earthquake means to determine in advance its place of origin, time and force and, consequently, largely to safeguard the people and material values from destruction. To a certain extent the problem of predicting the place and force of an earthquake is being solved by means of seismic zoning methods which have been well elaborated in the Soviet Union. Seismic zoning maps are state documents and every building organisation takes into account the extent of seismic danger in the given area, building up structures in compliance with antiseismic construction norms.

However, in many cases this proves to be not enough. It is highly important to know the time of earthquake origin.

As early as 1911 Academician Boris Golitsyn in Russia at the dawn of seismology noted a number of trends which, in his opinion, could contribute to the solution of the problem of earthquake prognostication. He pointed to the necessity of studying slow deformations of the earth's crust, variation in time of its elastic characteristics with the aid of translucent seismic waves, seismic regime, a detailed examination of the mineralogical compostion of springs and their regime (it concerns, of course, springs lying in seismoactive areas). It is worth noting that many trends in the field of earthquake prognostication are still developing on B. Golitsyn's lines.

Our knowledge of the nature of the earthquake focus is very limited yet. Most widespread is the viewpoint that the earthquake focus arises as a result of mechanical displacement of rock masses in the crust and mantle. A rather limited number of researchers assume that the earthquake focus is a result of physico-chemical processes taking place in the crust and mantle, that its nature is related to the phase and polymorphous transitions of the earth substance, and that tectonic manifestations of an earthquake - shifts, deformations - are the result of these processes.

* M.S. physical and mathematical sciences, Institute of Terrestrial Physics, USSR Academy of Sciences.
On the level of available materials the problem does not admit of easy solution, and there will be need for a fairly large complex of laboratory work for the study of rock behaviour under high temperature and pressure until a more definite viewpoint can be suggested.

At the same time, it is possible to assume, as is done by most seismologists, that for a certain period prior to a seismic catastrophic in the area of future focus some or other reasons account for a change of physical parameters of the medium and, as a result of this, the earth's surface undergoes deformation, and the electric and magnetic properties of the rocks are subject to alteration. At the present-day stage of our knowledge the problem boils down to the choice of parameters which would most effectively contribute to the study of the processes on the earth's surface in the future focus of a strong earthquake, so that the relationship between signal and interfering noise should be most favourable for observation. Calculations indicate that all possible variations in the physical characteristics of the medium will attenuate with distance, and it is therefore very important to bring observations closer to possible seismic sources.

Because of these specificities of the experiment, highly important is the choice of observation site. The solution of the earthquake prognostication problem makes it necessary to find such places where different earthquakes occur at maximum frequency.

A natural laboratory of earthquakes in the Soviet Union turns out to be the Surkhob and Khingou interfluve in Tajikistan, the area being arbitrarily known as Garmsky district. Here lies the centre of maximum effort for working out earthquake prognostication methods. Besides, certain results have also been obtained in the downstream area of the Naryn river at the Northern Tien-Shan in Central Asia. Much interest is attributed to the study of Kuril-Kamchatka earthquakes forming part of the Pacific seismic belt.

The work in earthquake prognostication is not likely to make good progress unless the 
experimental territory has been adequately studied. Very important here are geological methods. A detailed study of the tectonic activity of the seismoactive region and, in particular, the recently elaborated new methods for exposing modern tectonic movements lay down a basis for identification of most dangerous sections of the earth's crust and contribute to an accurate localization of places where strong earthquakes occur.

An important element of the work are detailed geophysical methods of reconnaisance type for the study of the upper part of the crust and of the crust as a whole with the aid of deep seismic probing. Naturally, there is a need for sufficiently detailed and accurate data about the distribution pattern of seismic tremors, and their depth, as obtained by the network of seismic stations.

The general investigation of the region forms a basis for detailed geophysical research. Let us discuss a classical trend - the study of the slow movements of the earth's crust by means of geodetic methods. High-accuracy levellings indicate that in the preparation period of a strong earthquake there occurs an intensive variation in the rate of movement of the earth's crust. Fig. I shows variation in deformation rate of the earth's crust before an earthquake with $\mathrm{M}=5.75$ in March 1969. Similar results were obtained in Japan prior to the Niagata earthquake in 1969. However, geodetic measurements, important as they are, are known to have a significant disadvantage, viz. they cannot be made but at relatively long intervals. Therefore the study of the earth's surface dips and deformations adds up significantly to this part of the work. Fig. 2 makes use of the data obtained in the Naryn valley to show the variation of dips before two earthquakes with epicentres lying close to the setup. One was very weak with $\mathrm{M}=2.5(=2 \mathrm{~km})$ and in the case of the other $M=4.7(=6 \mathrm{~km})$. In both cases one can clearly see a variation in the nature of dips a few hours before the earthquake. Characteristically, the stronger earthquake, but the one lying 80 kilometers away from the dipmeters, did not yield any significant features of the dips.

In this respect very interesting appear to be deformation setups which record anomalous deformations at great distance. Observations at the Northern Tien Shan give us a few instances of an anomalous variation of dips before a relatively strong tremor. It is now evident that the efficiency of all the methods for studying deformations of the earth's crust can be raised solely by increasing the number of observation points and constructing a "deformation field". It is on these lines that our work is being conducted at present.

\section{Electromagnetic Observations}

An interesting complex of work has been carried out by oleg Barsukov's group for studying the electric conductivity of rocks over large bases. It is to be noted that efforts to identify variations in electric conductivity in the natural electromagnetic field before an earthquake were unsuccessful. Therefore it was suggested that a field artificially excited by a generator should be used for electric conductivity studies. This work is unique and, as can be judged from literature, has never been used for prognostication purposes. Using a powerful generator enables a signal much superior to natural noises to be obtained and in this way qualitatively different conditions for staging experiments to be produced.

The generator group was set up in such a way that in one direction from it the receiving setups approached as close as possible to earthquake sources, whilst in the other direction they moved away. The results were quite significant. Within one and a half years three earthquakes occured in the observation area, the force in the epicentre attaining $\mathrm{V}-\mathrm{VI}$ points. In every case there was observed a characteristic variation in electric conductivity at the setup close to the epicentres. In the opposite direction no tangible effect was practically obtained (fig. 3). The experiment which is still in progress reveals, first of all, the local nature of the effect itself and, consequently, dictates a careful choice of the site, and, secondly, shows for the first time the effect of a significant variation in electric conductivity of rocks in connection with an earthquake.

Thus, given an adequate organisation of observations for electromagnetic symptoms of an earthquake, it is quite possible to obtain a very valuable material on geophysical characteristics preceding a strong earthquake.

There are grounds for an assumption that prognostication specificities are inherent in the regime of thermal springs in the area of tectonic dislocations. Appropriate evidence is found, for instance, in the data on the variation in radon content in the period preceding the Tashkent earthquake in 1966 in one of the boreholes lying close to the epicentre (fig. 4).

Deformation, dip, and electromagnetic measurements, even though they furnish materials on earthquake forerunners, bring us closer to the solution of not more than one prognostication problem - the origin time of a strong tremor. This is, however, not enough. One should also know its place and force both on general considerations and for a correct choice of the site for undertaking methodo- 
logical work.

A large volume of work has been conducted on these lines at the Institute of Terrestrial Physics, USSR Academy of Sciences, primarily in the Gramsky district (Tajikistan).

\section{Frequency Laws}

In processing the data on dynamic features, obtained in earthquakes, we noticed the highfrequency composition of transverse waves in weak earthquakes occuring in the period preceding a strong tremor, when relatively low frequencies in the transverse waves of aftershocks predominate. An assumption was made to the effect that the focus area in the period of stress accumulation consists of two types of sources. In an ordinary placid regime of tectonic process there occurs a continuous slow movement, the rocks, so to speak, slipping down along one or other weakened zone. In preparation to a strong earthquake the normal process of movement discontinues (calm in the area of future focus is a rather characteristic phenomenon to be observed quite frequently). In that period seismic processes manifest themselves, mainly, in the form of a major rock rupture. It is this stage of the process that is characterized by high-frequency vibrations.

Fig. 5 shows the distribution pattern of high-frequency tremors in the period directly preceding a strong earthquake. They lie on the boundary of the area of process development, the size of which is, apparently, closely related to the force of preparing earthquake and may also serve for evaluation of its time of origin. True, in judging on the time of possible tremor one must be very careful.

Fig. 6 shows the degree of separation into foreshock and aftershock succession of an earthquake according to frequency criterion.

\section{The Mechanism of Earthquake Focus}

Using a great number of stations for seismic observations, we were able to study the mechanism of earthquake focus by means of methods elaborated by Anna Vvedenskaya.

In most cases the studies were made in connection with strong earthquakes. In the past years they were increasingly applied to determine the mechanism of weak tremors as well. However, in most cases the observation material was rather limited. We have tried to go over to mass processing of data so as to be able to examine on a wealth of material not only the statics of the mechanism, but also to attempt an evaluation of its variation in time. The data processing was made both in the Gramsky district and in the Naryn downstream area.

As a result of the stresses arising in the crust or mantle there occurs a shift characterized by two systems of stress axes compression and expansion, by orientation of the plane and the sign of its movement. In this case the sign of movement is conventionally assumed to be determined by the motion of the interior wing - in upward movement the sign is said to be positive, in downward movement, negative. Since a given system of forces does not eliminate uncertainty in the orientation of rupture planes, the latter are given in two possible versions. In this case it is important that a double orientation of motion planes fails to affect in either case the sign of movement.

The three-dimensional system of stress axes, though endowed with certain laws, does not reveal itself otherwise than by way of statistical processing and not very clearly at that. The situation is far better with signs of movement. They have been found to follow fairly clear-cut spatial laws.

It is precisely where the motion is subject to a change, in the foci, that happens to be the area coinciding with strong earthquakes (fig. 7). It is an extremely important result because it admits of an absolutely new approach to the zoning of seismic territory and, moreover, enables the site most promising for elaboration of prognostication methods in time to be appraised instrumentally.

However, the mechanism of earthquake foci appears to be of interest not from the view point of zoning alone. The study of the behaviour of stress axes reveals that in the area of earthquake preparation there occurs a perceptible reorientation of stress axes in time. (Shown in fig. 8 are a few instances of varying orientation of stress axes before strong tremors.)

\section{Velocity and Amplitude Relationships}

Very interesting appears to be the work carried out in the Gramsky district for studying velocity and amplitude relationships of longitudinal and transverse waves.

Making use of a sufficiently dense network of seismic stations, we tried to evaluate velocity variation of longitudinal waves in time. The results obtained were not very encouraging.

At the next stage of work we got down to determining velocity relationships and, secondly, for evaluating the variation in velocity relationships with depth. The processing of obtained material revealed some areas of consistently reduced velocity values. It is these areas coinciding in most cases with the areas of a different sign of motion, as to the earthquake focus mechanism, that are 
the sites of strong earthquakes. Thus, by a rather different approach we have derived a new technique of territorial zoning.

After we had succeeded in identifying average characteristics of velocity relationships in a volume, we attempted to study the behaviour of velocity relationships in time. It was found out that in every case of an earthquake in the 12 th or 13 th class $(M=4.5$, 5.25) there occurs in its preparation area an anomalous change in velocity relationships of longitudinal and transverse waves. The law observed in that case was as follows: the stronger the earthquake, the longer the volume persists in an anomalous state (fig. 9).

Determination of the focus mechanism being a fairly laborious undertaking, an attempt was made, alongside of studying the velocity relationships, to evaluate the behaviour of amplitude relationships of longitudinal and transverse waves in time. The results of the work are shown on the graph in Fig. 10. We obtained here too a variation in the relationships prior to a strong tremor. Generally speaking, this result could be expected from the data on time variations in stress axes.

Undoubtedly, much of what has just been discussed is in need of rigorous checkup. Nevertheless, the material accumulated by now holds promise of a successful solution of the problem.

Novosti Press Agency. 

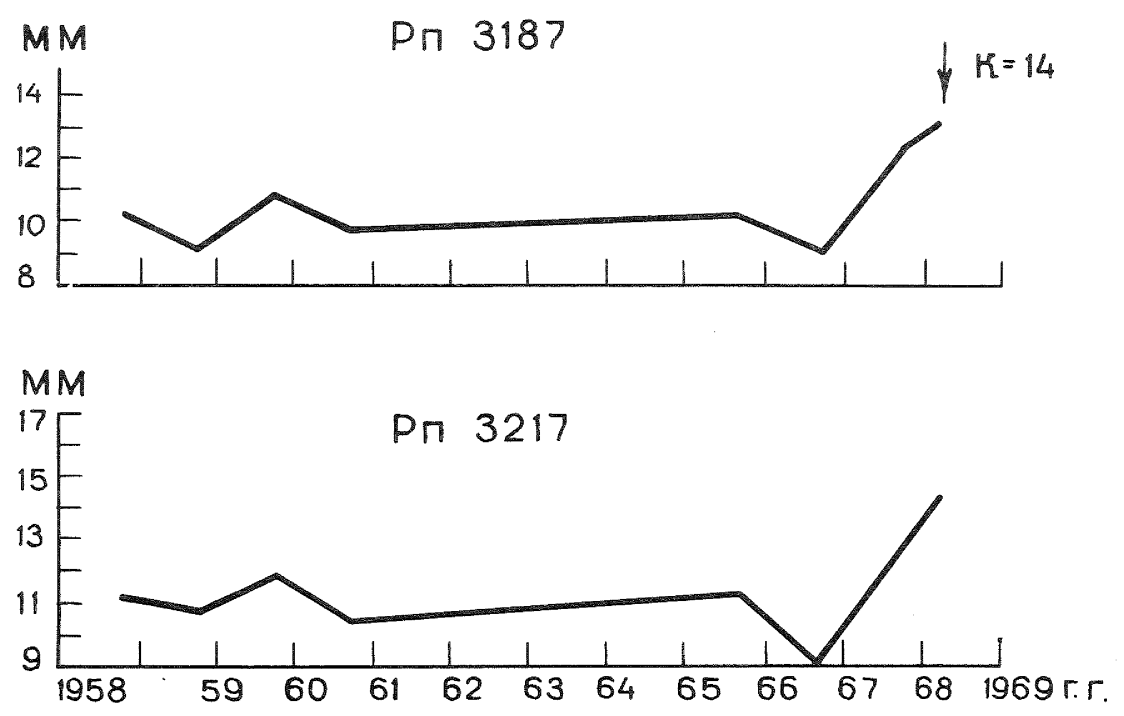

Fig.1 A sharp increase in the rate of earth's surface deformation on the eve of earthquake with $\mathrm{M}=5.75$ in March 1969.
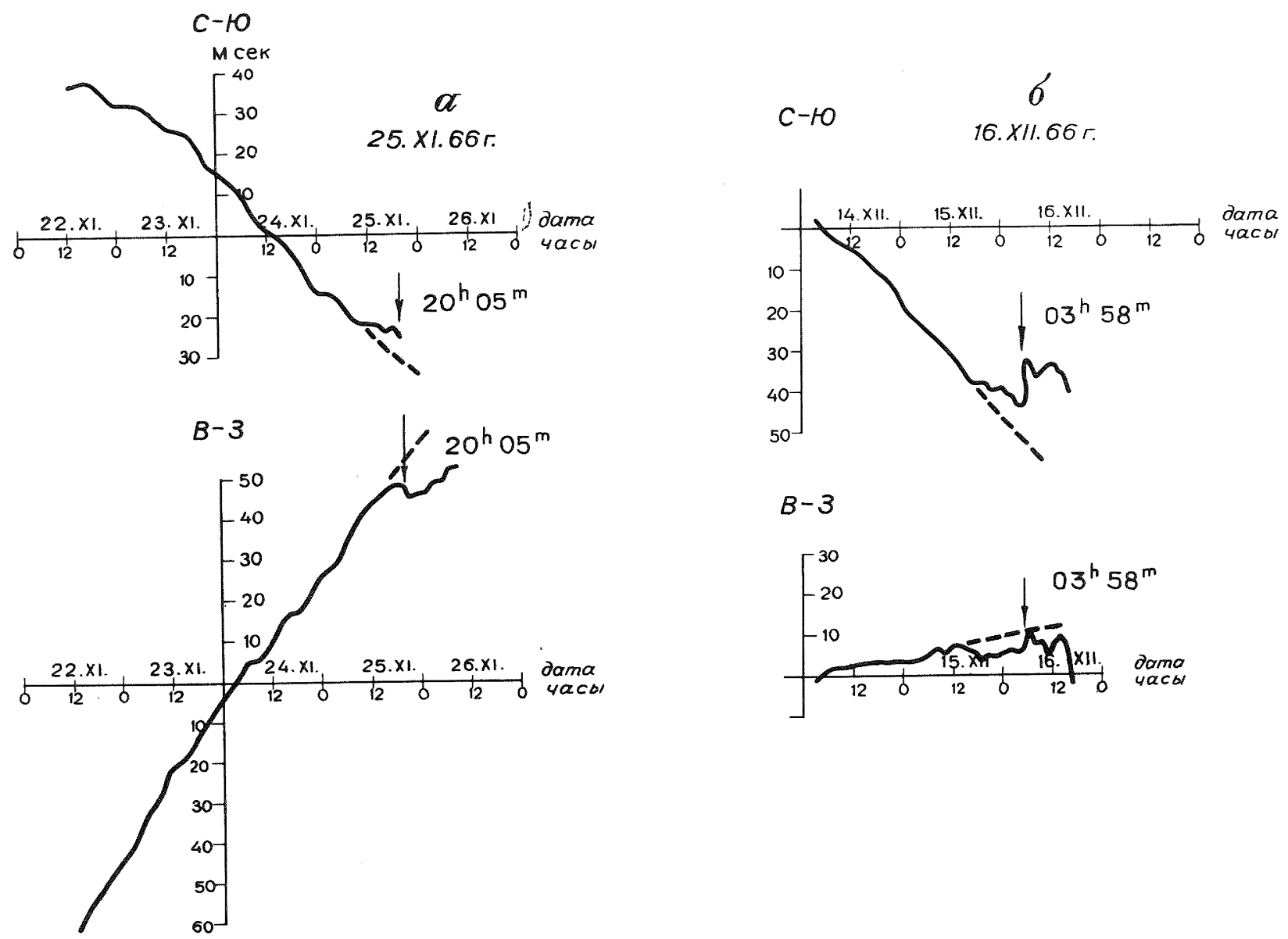

B-3

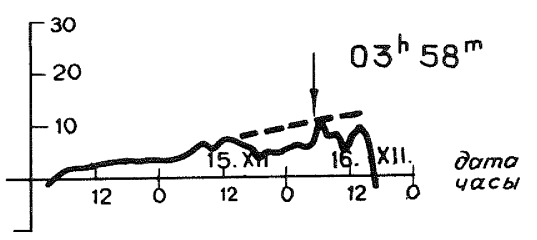

Fig.2 Variation of earth's surface tilt:

a) before a weak, but very close earthquake $(\Delta=2 \mathrm{~km})$;

b) perceptible tremor $(\Delta=9 \mathrm{~km})$. 


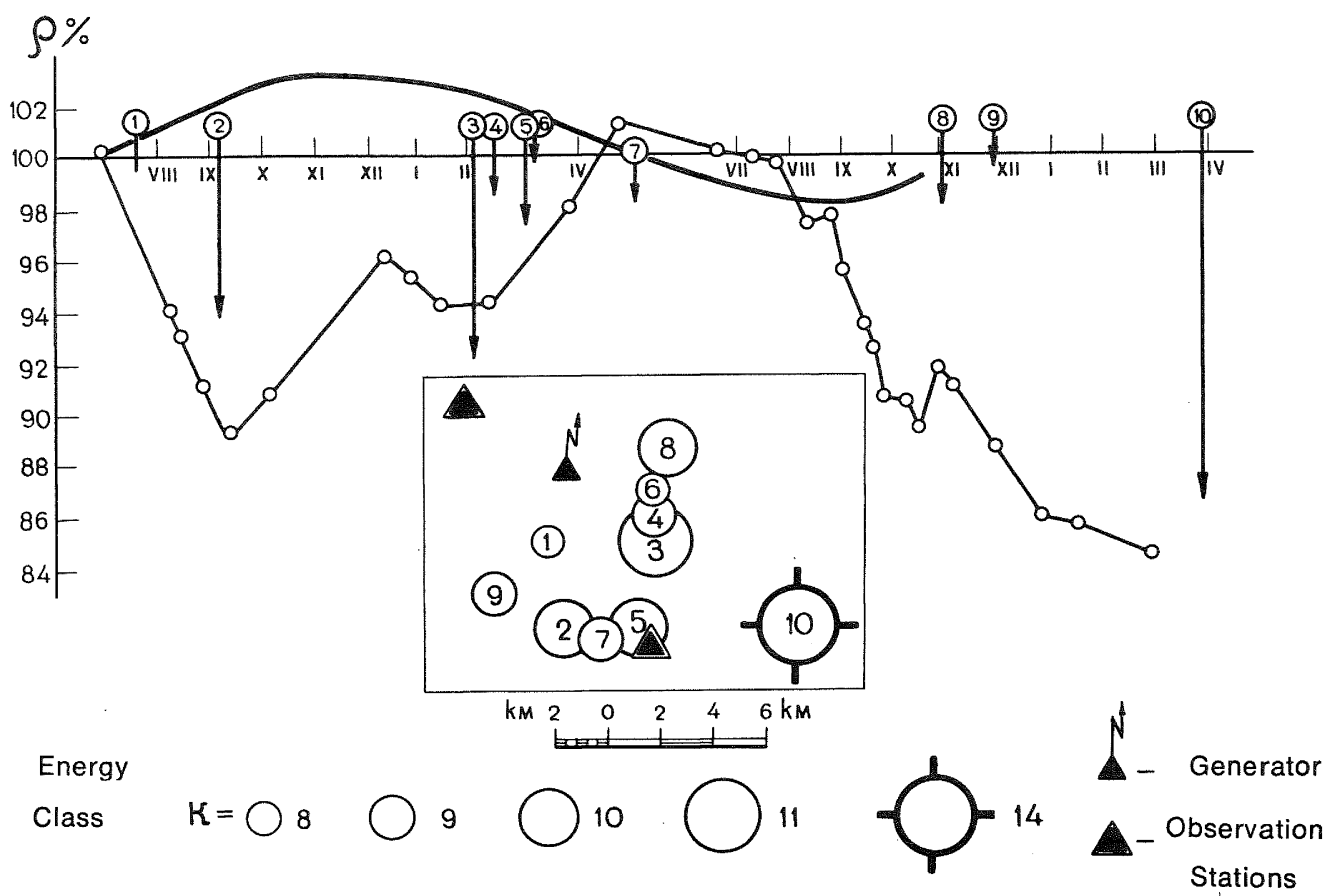

Fig.3 Specific resistance variation. Upper curve (thick) - at the station removed from the epicentres; lower curve-at observation stations in the vicinity of epicentres. Shown inside the square is the layout of observation system and epicentres. $\mathrm{K}=1 \mathrm{gE}$ joules 


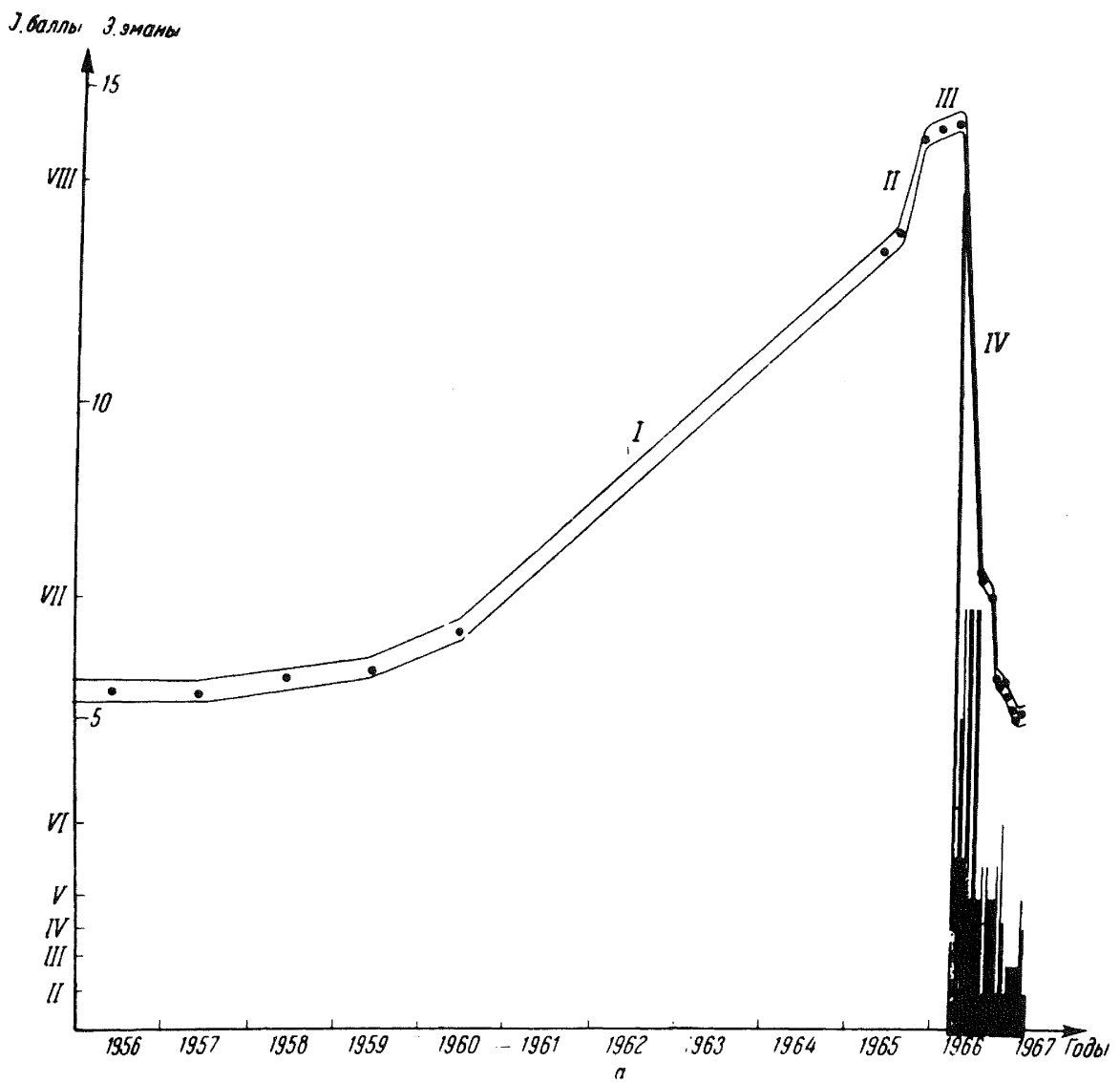

Fig.4 Variation of radon concentration in thermomineral water near Tashkent:

a) from 1957 to 1967; marks on horizontal axis indicate years, on vertical axis--intensity of underground tremors in points of force and radon concentration in ems ( $1 \mathrm{em}=1 \cdot 10^{-10}$ curie/litre). Blue points indicate radon concentration measurements. The width of the averaging strip corresponds to the magnitude of measurement error. Roman numbers stand for rock deformation stages; blue pillars stand for Tashkent earthquake and its aftershocks. 

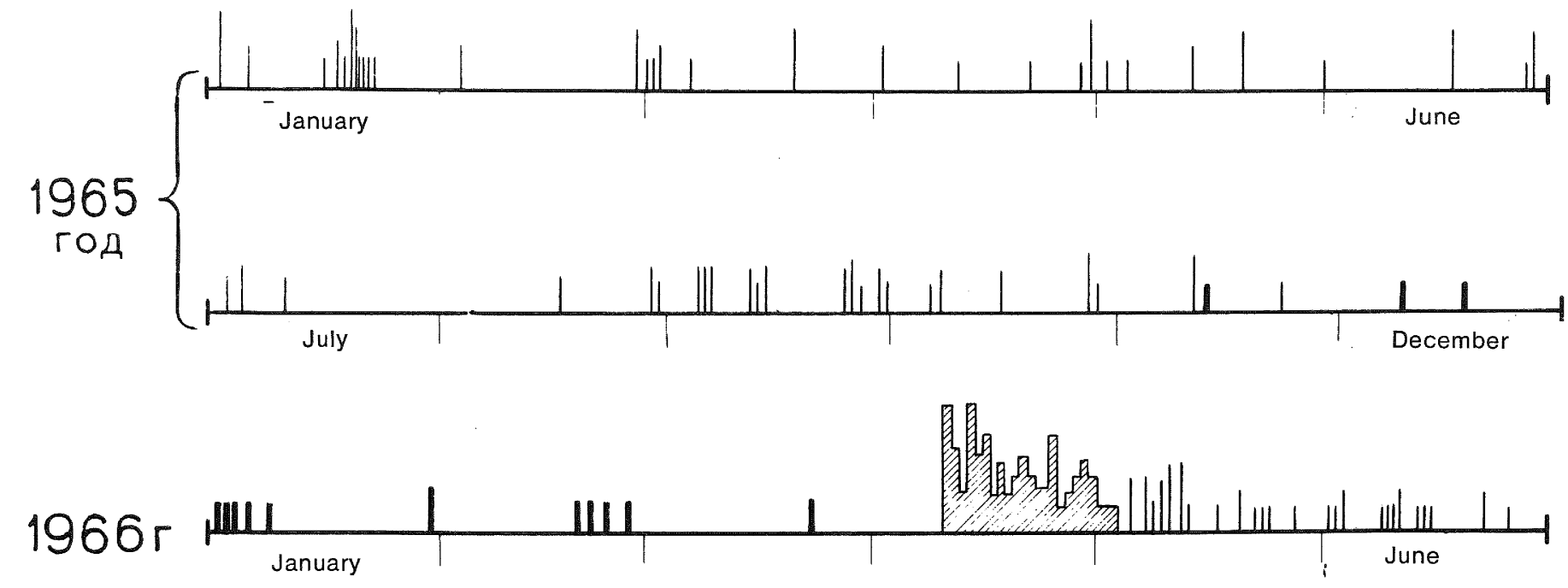

$\perp$ background $3 / \mathrm{tr}, \perp$ Foreshock $\quad \perp$ principal $3 /$ tr and aftershocks

Fig.5 Distribution of low-frequency (thin lines) and highfrequency (thick lines) microearthquakes before a strong tremor.

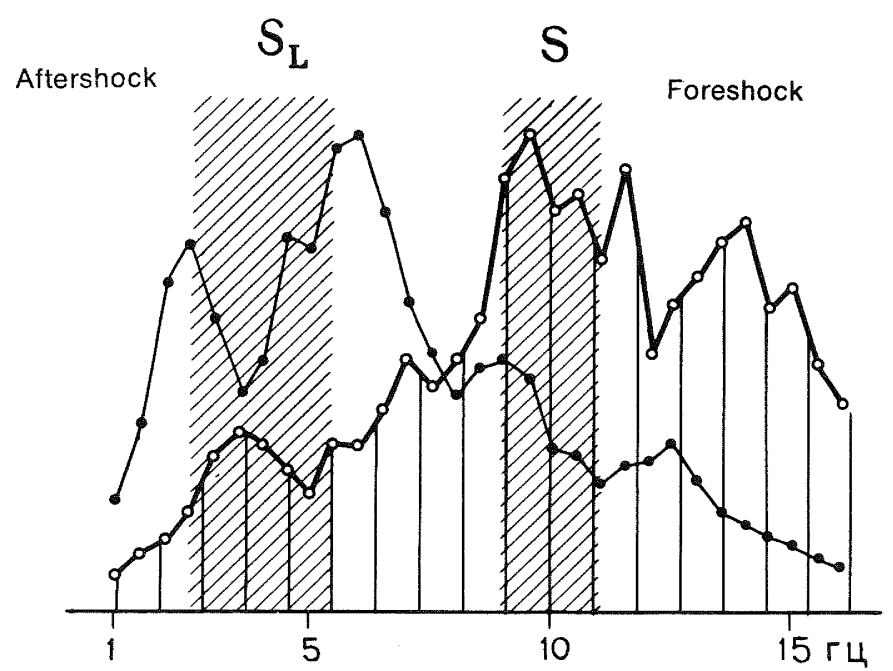

Fig.6 Division of foreshock and aftershock microearthquakes according to transverse wave frequency. 


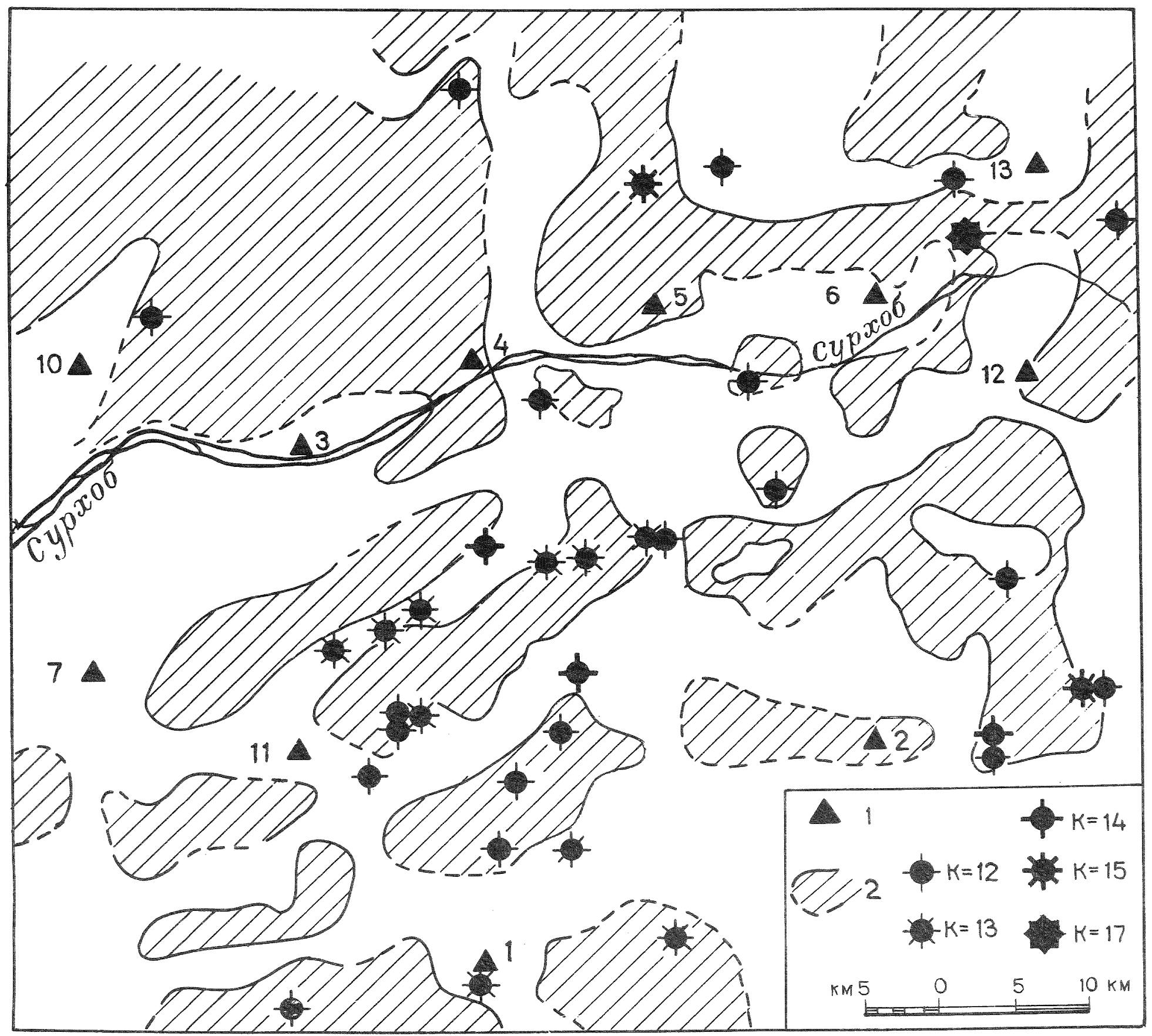

Fig.7 Division of Gramsky district into blocks with a different sign on motion of rupture planes in earthquake foci:

1 - Seismostation;

2 - Areas with a positive sign of motion $\mathrm{K}=\operatorname{lgE}$ joules 


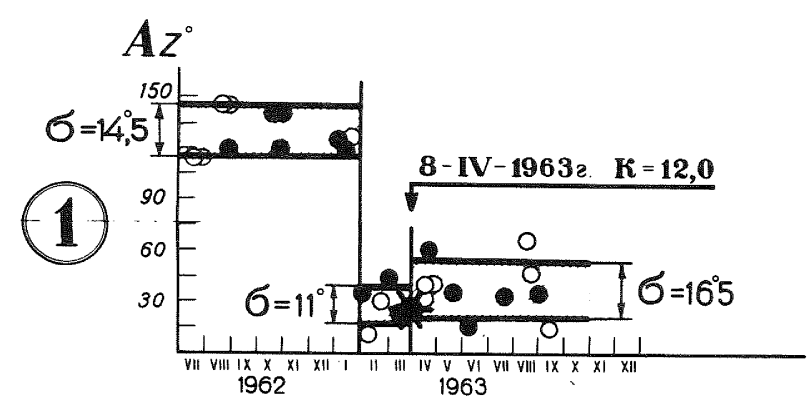

$0,+$

- ${ }^{-\infty}$

(1) Naryn district

(3) Garmsky district
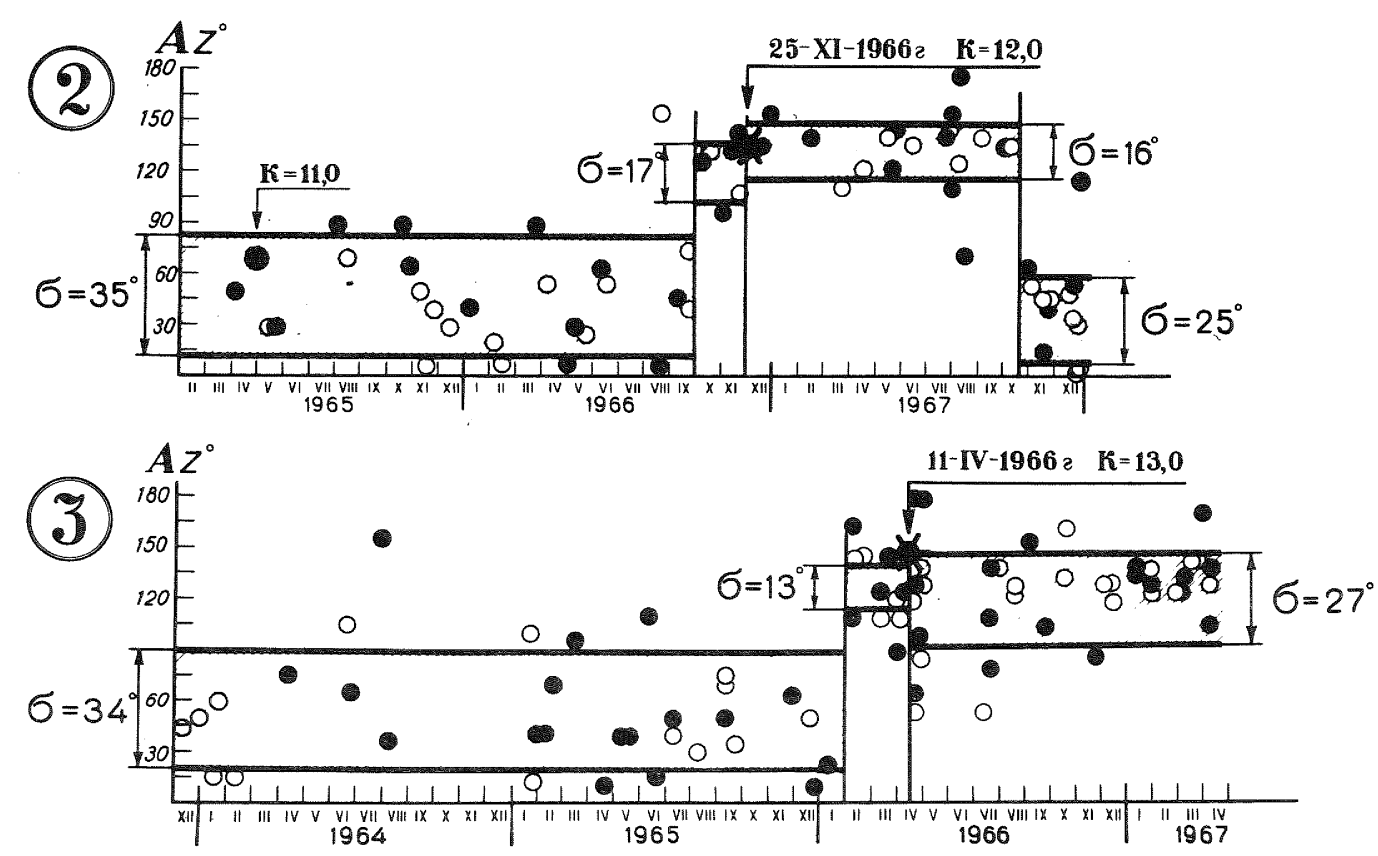

Fig.8 Variations in the azimuths of stress axes before and after a strong earthquake. 


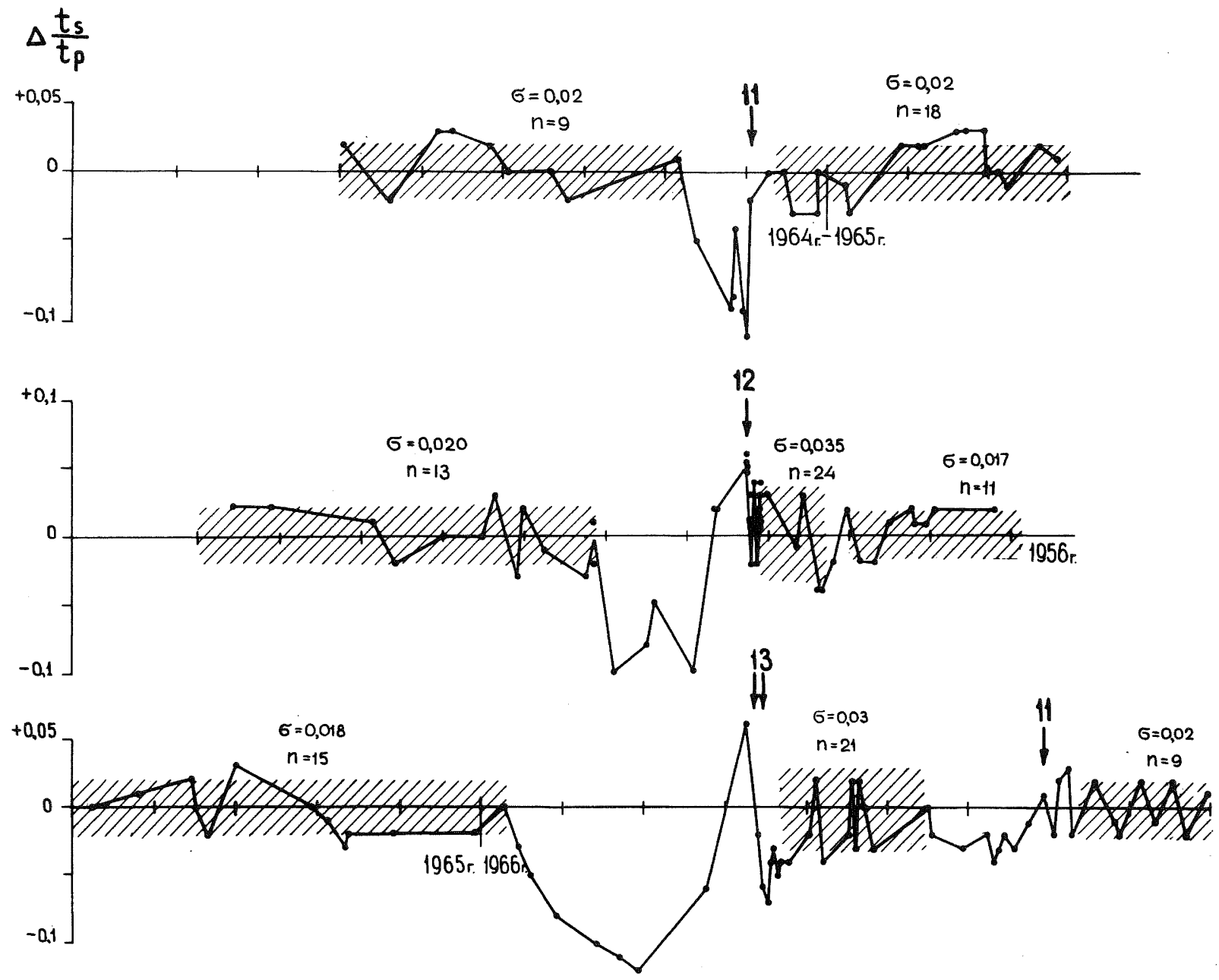

Fig.9 The amount of anomalies in velocity relationships of longitudinal and transverse waves varies with increasing force of earthquake. 


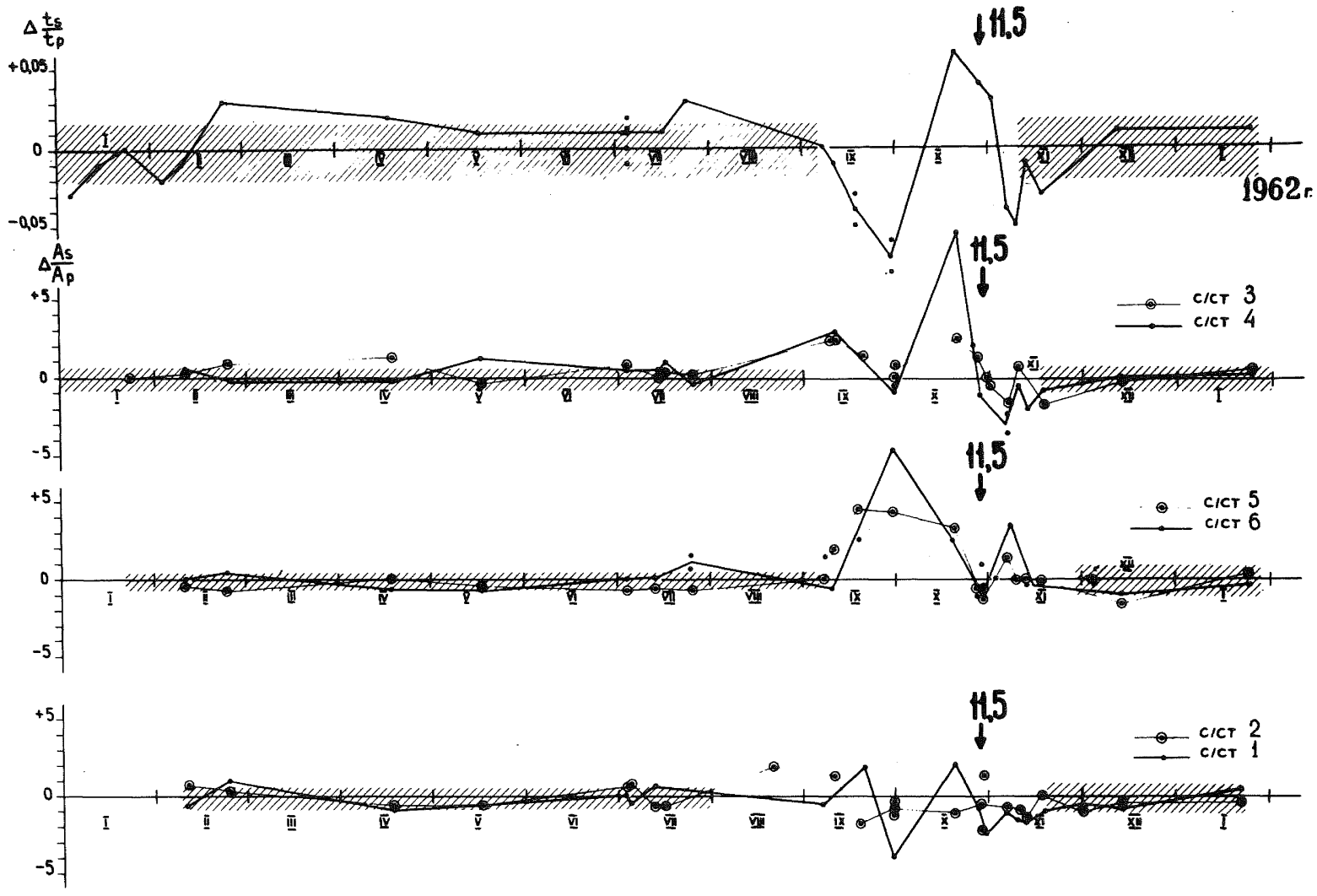

Fig.10 Variation in velocity and amplitude relationships of longitudinal and transverse waves at different stations. 